\title{
AMENDMENTS
}

\section{Publisher Correction: Climate-driven changes in the composition of New World plant communities}

\author{
K. J. Feeley (D), C. Bravo-Avila (D), B. Fadrique (D), T. M. Perez (D) and D. Zuleta (D)
}

Correction to: Nature Climate Change https://www.nature.com/articles/s41558-020-0873-2, published online 17 August 2020.

In the version of this Article originally published, the scale bar labels "Change in TR $\left({ }^{\circ} \mathrm{C} \mathrm{yr}^{-1}\right)$ " in Fig. $3 \mathrm{c}$ and "Change in $\mathrm{MR}\left(\mathrm{mm} \mathrm{yr}^{-1}\right)$ " in Fig. $3 \mathrm{~d}$ were incorrect; instead the labels should have read "Thermophilization rate $\left({ }^{\circ} \mathrm{C} \mathrm{yr}^{-1}\right)$ " and "Mesophilization rate ( $\left.\mathrm{mm} \mathrm{yr}^{-1}\right)$ ", respectively. This has now been corrected in all online versions.

Published online: 10 September 2020

https://doi.org/10.1038/s41558-020-00926-2

(c) The Author(s), under exclusive licence to Springer Nature Limited 2020

\section{Publisher Correction: A recent decline in North Atlantic subtropical mode water formation}

Samuel W. Stevens $\mathbb{D}$, Rodney J. Johnson, Guillaume Maze $\mathbb{D}$ and Nicholas R. Bates

Correction to: Nature Climate Change https://doi.org/10.1038/s41558-020-0722-3, published online 23 March 2020.

In the version of this Article originally published, in Fig. $2 \mathrm{~d}$ and $\mathrm{f}$, in all the $y$-axis values ' $\times 10^{-7}$ ' was incorrect and should have been ' $\times 10^{7}$ '. This error has now been corrected in the online versions of this Article.

Published online: 22 September 2020

https://doi.org/10.1038/s41558-020-00932-4

(C) The Author(s), under exclusive licence to Springer Nature Limited 2020 